\title{
Reply to comment on "Primates in the Eocene" by Gilbert and Maiolino (2015)
}

\author{
Philip D. Gingerich ${ }^{1}$
}

Received: 30 March 2015 / Accepted: 14 April 2015 /Published online: 7 May 2015

(C) Senckenberg Gesellschaft für Naturforschung and Springer-Verlag Berlin Heidelberg 2015

My recent review titled "Primates in the Eocene" emphasised time as an essential variable in the study of primate evolution and primate phylogeny. The Eocene is important for primate evolution because this is the geological epoch when true primates (sometimes called euprimates) first appeared. The Eocene is interesting too because the earliest primates include two groups, Tarsioidea and Adapoidea, that are so similar early in their history that members of one group have often been mistaken for members of the other. Similarity in time, place, and morphology to the point of confusion is compelling - if not infallible - evidence of a close phylogenetic relationship. And still, in spite of this early linkage, some authors, such as Gilbert and Maiolino (2015), would classify Tarsioidea and Adapoidea in separate suborders, Haplorhini and Strepsirrhini respectively, in the order Primates.

Maiolino et al. (2012) described the morphology of pedal distal phalanges in the early Eocene primate Notharctus tenebrosus and concluded that Notharctus had a grooming claw on the second toe, on pedal digit II. In their comment, Gilbert and Maiolino (2015) claim that pedal distal phalanges bearing grooming claws are readily separated from other 'unguis' forms on the basis of their facet-shaft angle (FSA), and volar feature length (VFL) as a proportion of total phalanx length (TPL). However, FSA and VFL/TPL are related to the positioning of distal phalanges in a grasping foot and by themselves indicate little about phalanx shape.

As background it is important to note that Koenigswald, Habersetzer, and Gingerich (2012) described and analysed a

Philip D. Gingerich

gingeric@umich.edu

1 Museum of Paleontology, University of Michigan, Ann Arbor, Michigan 48109-1079, USA broad range of primate distal phalanges, recognizing scutiform, falciform, piciform, and columnar distal phalanges on the basis of morphology, with scutiform phalanges interpreted as nail-bearing in prosimians, falciform phalanges interpreted as claw-bearing, piciform phalanges interpreted as bearing grooming claws, and columnar phalanges interpreted as nail-bearing in anthropoids.

Our principal components analysis of pedal distal phalanx measurements indicated that Notharctus had grooming claws on digits II and III (von Koenigswald et al. 2012). Discriminant analysis of feet with and without grooming claws, analysed phalanx by phalanx, indicated that Notharctus lacked grooming claws. Discriminant analysis of feet with and without grooming claws, analysed foot by foot rather than phalanx by phalanx, indicated that Notharctus falls in an ambiguous middle ground between primates with grooming claws and primates that lack them.

Gilbert and Maiolino (2015) question my recent characterisation of the morphology of pedal distal phalanges in Notharctus as 'ambiguous,' arguing, as they did before (Maiolino et al. 2012), that morphology shows Notharctus to have had a grooming claw on pedal digit II. However, the strongest case for 'ambiguity' in the interpretation of Notharctus grooming claws is provided by Maiolino et al. (2012) in their figure 13 (reproduced here as Fig. 1). Notharctus pedal distal phalanges all have 'SW-3/4/TPL' values in the ungulae range, and most of these are beyond the tail of the grooming claw range. The one Notharctus ungule known to represent the pedal distal phalanx of digit II (arrows in Fig. 1) is far beyond the range of values observed for grooming claws.

Gilbert and Maiolino (2015) can call the distal phalanx of pedal digit II in Notharctus a claw, but calling it a claw does not make it a claw - and it is not a claw unless it has the form of a claw in all three dimensions. A spoon looks like a fork in 


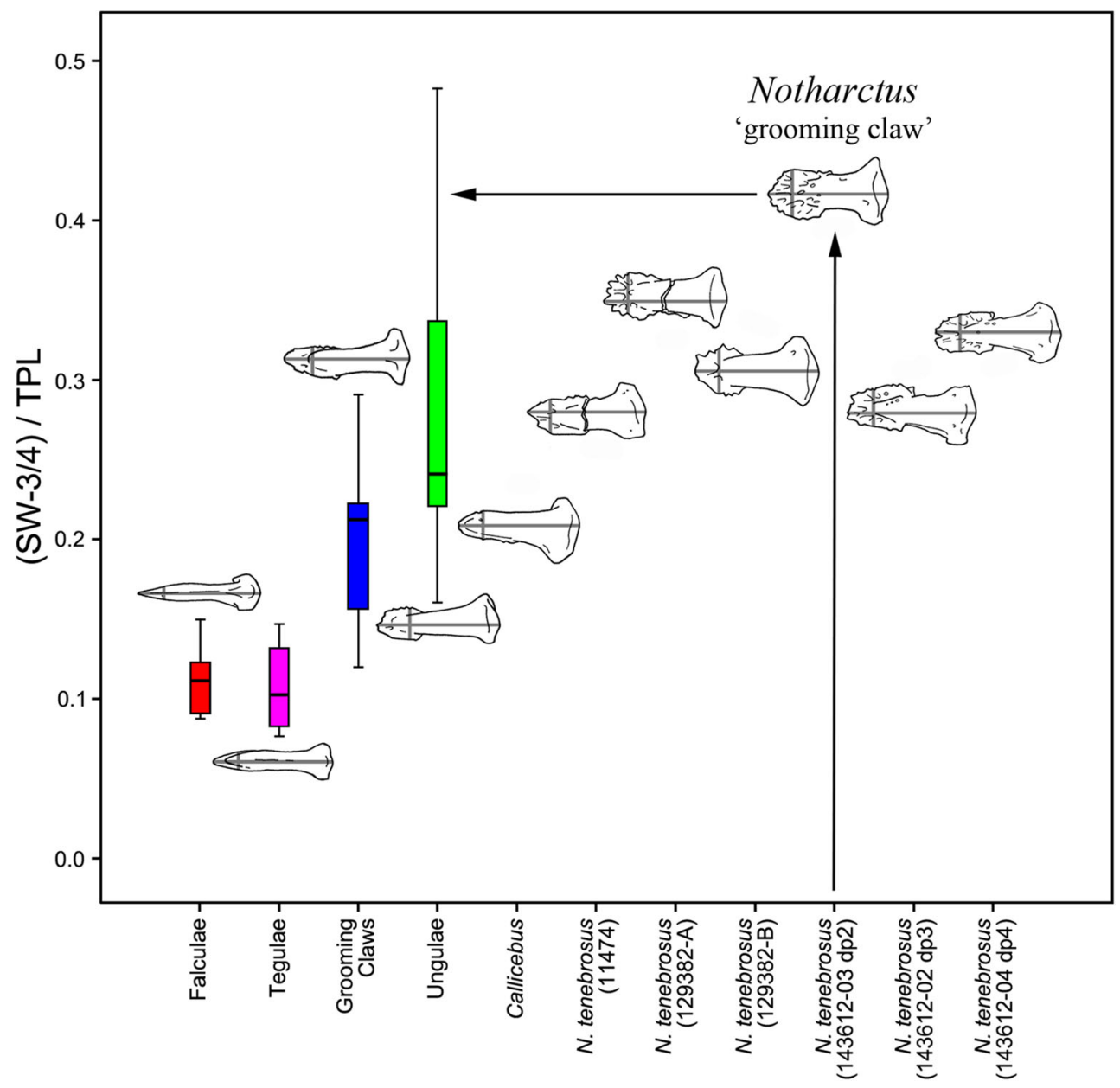

Fig. 1 Pedal distal phalanges of Notharctus in dorsal view. Shaft width measured at three-quarters the length of the shaft $(S W-3 / 4)$ was divided by total phalanx length (TPL). Boxplots are statistical representations of distal phalanx 'SW-3/4/TPL' values for falculae, tegulae, grooming claws, and ungulae of extant primates. For comparison, the median specimen from each extant group is illustrated: Tupaia glis represents the falculae group; Callithrix sp., tegulae; Galago senegalensis, grooming claws; Saimiri sp., ungulae. Here Notharctus pedal distal phalanges all have 'SW-3/4/TPL' values in the ungulae range, and most are beyond the tail of the grooming claw range. The one Notharctus ungule known to represent the pedal distal phalanx of digit II (arrows) has a 'SW-3/4/TPL' value far beyond the range observed for grooming claws. Illustration is reproduced from Maiolino et al. (fig. 13, 2012) with the arrows added lateral view, but that does not make it a fork. The presence of a claw in Notharctus is at best, as I wrote, 'ambiguous' (Gingerich 2012). Maiolino et al. (2012, fig. 13 )(Fig. 1 here) seems to show that no claw was present at all. Further, if an ungule said to be a grooming claw does not have the shape of a claw, then it is hard to imagine it was used for grooming.

Gilbert and Maiolino (2015) claim that my cladistic interpretation of Notharctus and Darwinius (Fig. 2), based on a Maiolino et al. (2012) dataset, is "demonstrably false" because they find a different set of most parsimonious cladograms. I analysed the 30-character data matrix in Section 16 of the supplementary documentation of phylogenetic analyses provided by Maiolino et al. (2012). This represents the original character list and scoring of Gingerich et al. (2010) as modified by Maiolino et al. (2012), who rescored some characters and added the taxa Notharctus and Catopithecus. In addition, as stated in Gingerich (2012), I corrected Maiolino et al.'s character 9 score for Notharctus to '1,' representing its largely carotid blood supply to the brain (Gingerich 2012).

Gingerich et al. (2010) compiled the 30-character data set as a list of characteristics cited by authors, principally Hill (1953, 1955) and Fleagle (1999), to distinguish Strepsirrhini and Haplorhini. Guiding principles included (1) representation - representation of the full range of characteristics distinguishing Strepsirrhini and Haplorhini as high-level taxa; (2) simplicity - inclusion of a trait no more than once if possible; and (3) independence - choice of characteristics that are developmentally, functionally, and evolutionarily as independent of each other as possible. Phylogenetic parsimony is a statistical concept that depends critically on character representation and character independence. 


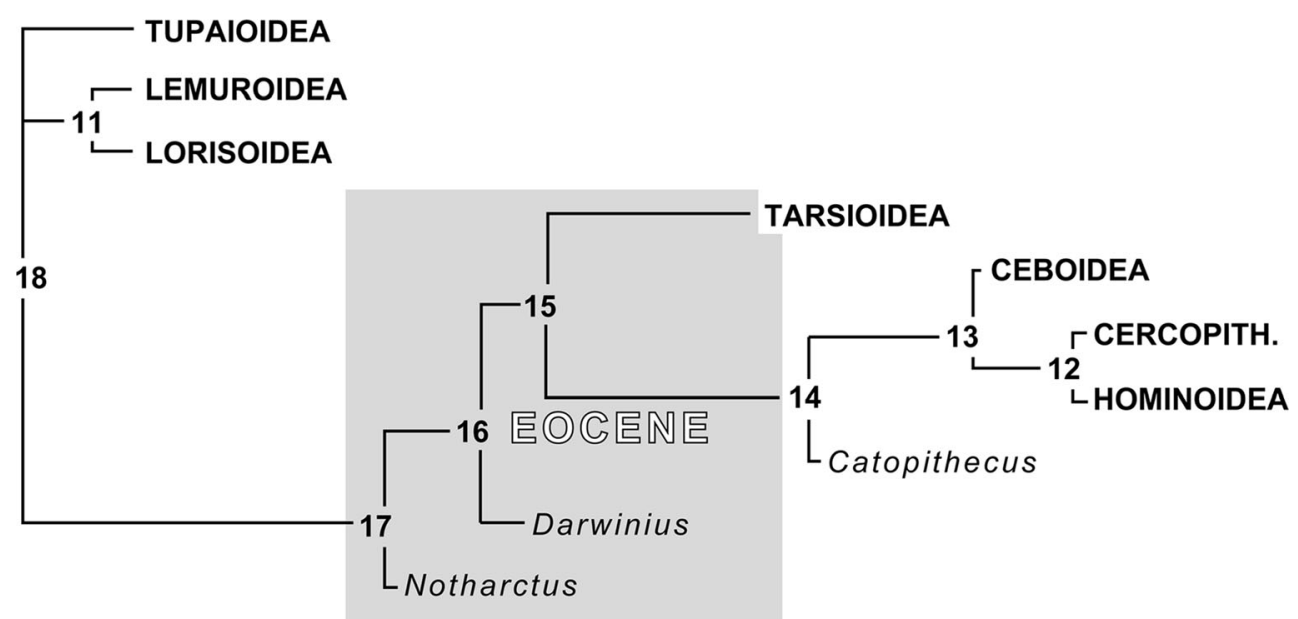

Fig. 2 Phylogram of Gingerich (2012) showing the most parsimonious interpretation of cladistic relationships of Eocene Notharctus, Eocene Darwinius, and Oligocene Catopithecus to living Tupaioidea, Strepsirrhini (Lemuroidea and Lorisoidea), and Haplorhini (Tarsioidea, Ceboidea, Cercopithecoidea, and Hominoidea) based on the 30-character data matrix in Section 16 of the supplementary documentation of phylogenetic analyses provided by Maiolino et al. (2012). Character 9 was corrected to ' 1 ' for Notharctus, representing its largely carotid blood

The Maiolino et al. (2012) dataset that I analysed in 2012 has 30 characters, while the dataset discussed by Gilbert and Maiolino (2015) has 39 characters. Thus, contrary to Gilbert and Maiolino (2015), my analysis is not "demonstrably false": we did not analyse the same data and find a different result. Under the circumstances it would be reasonable to conclude that cladistic results depend on the data analysed. I would not claim that the Gilbert and Maiolino (2015) cladogram based on 39 characters is "demonstrably false" any more than I think they are justified in applying this label to my 30-character cladogram. Any result is contingent on the data analysed.

I did not use the 39-character data matrix in Section 18 of the supplementary documentation of phylogenetic analyses provided by Maiolino et al. (2012), repeated in the electronic supplementary material of Gilbert and Maiolino (2015), because seven of the nine characters added to my 30-character list by Maiolino et al. (2012) are related to the ankle and foot (which were already represented in the original 30-character list). There is little question that the grasping feet of Tarsioidea and Adapoidea were inherited from a common ancestor with grasping feet, but this does not justify flooding a matrix with correlated characters of the ankle and foot. This addition of foot characters could be countered by the addition of correlated dental characters, with argumentation continuing ad infinitum to prove what we already know: construction of cladograms is influenced by choice of characters and by their statistical dependence and independence. The only real test of a cladistic hypothesis of evolutionary relationships is its mapping onto a fossil record through geological time, and this is where the phenogram shown in Fig. 2 stands out as consistent in relation to the primate fossil record (Gingerich 2012). supply to the brain. Some interpretations of Maiolino et al. (2012) are questionable, but even here Darwinius and Notharctus are stem haplorhines grouping with Tarsioidea and higher primates rather than the strepsirrhine Lemuroidea, and Lorisoidea. The Eocene is shaded. Comparison with the primate fossil record (Gingerich 2012) shows diversification of Tarsioidea and Adapoidea happened at the beginning of the Eocene, and diversification of later higher primates happened at the end of the Eocene or beginning of the Oligocene

I will end by emphasizing three points in my 2012 review of "Primates in the Eocene": (1) different primates lived at different times; (2) primates evolved through time; (3) the Eocene is interesting because the earliest primates include two groups, Tarsioidea and Adapoidea, which are so similar early in their history that members of one group have often been mistaken for members of the other. Similarity in time, place, and morphology to the point of confusion is compelling evidence of close phylogenetic relationship. If Eocene tarsioids were haplorhines, then it is almost certain that Eocene adapoids were haplorhines also. If Eocene tarsioids were strepsirrhines, then it is almost certain that Eocene adapoids were strepsirrhines also. We can not examine their noses to solve this issue. We can only trace living haplorhines and strepsirrhines back from the present, through the fossil record, and try to see where they converge. Adapoids retain some primitive characteristics, as do tarsioids, but these are less important than the derived characteristics each has linking them to primates found later in time.

\section{References}

Fleagle, J. G. (1999). Primate Adaptation and Evolution (2nd ed.). San Diego: Academic Press.

Gilbert, C. C., \& Maiolino, S. A. (2015). Comment to 'Primates in the Eocene' by Gingerich (2012). Palaeobiodiversity and Palaeoenvironments, 95, 1-5. doi:10.1007/s12549-015-0184-1.

Gingerich, P. D. (2012). Primates in the Eocene. Palaeobiodiversity and Palaeoenvironments, 92, 649-663. doi:10.1007/s12549012-0093-5.

Gingerich, P. D., Franzen, J. L., Habersetzer, J., Hurum, J. H., \& Smith, B. H. (2010). Darwinius masillae is a haplorhine - reply to Williams 
et al. (2010). Journal of Human Evolution, 59, 574-579. doi:10. 1016/j.jhevol.2010.07.013.

Hill, W. C. O. (1953). Primates: comparative anatomy and taxonomy. IStrepsirhini, a monograph. Edinburgh: Edinburgh University Press.

Hill, W. C. O. (1955). Primates: comparative anatomy and taxonomy. II-Haplorhini: Tarsioidea, a monograph. Edinburgh: Edinburgh University Press.

Koenigswald, W. von, Habersetzer, J., \& Gingerich, P. D. (2012). Pedal distal phalanges of the Eocene adapoids Europolemur and
Darwinius compared to phalanges of Notharctus and other primates. Palaeobiodiversity and Palaeoenvironments, 92, 539-565. doi:10. 1007/s12549-012-0096-2.

Maiolino, S., Boyer, D. M., Bloch, J. I., Gilbert, C. C., \& Groenke, J. (2012). Evidence for a grooming claw in a North American adapiform primate: implications for anthropoid origins. PLoS One, 7, e29135. doi:10.1371 \journal.pone. 0029135. 